\title{
In memory of Noel Blake
}

\section{Walter E. Berdon}

Received: 25 March 2010/Accepted: 26 March 2010

(C) Springer-Verlag 2010

Noel Blake was a dynamic, charming and friendly colleague whom I met on several occasions in Dublin. He and I talked about sailing but never got to sail together. Incredibly he and his first wife, Ann, both died of stomach cancer.
We who knew him will remember him fondly, including his dancing the Irish jig at dinners of the ESPR in Dublin.

Pediatric radiology is a global community of colleagues and friends. Noel will be missed.

W. E. Berdon $(\square)$

Department of Radiology, Columbia University

College of Physicians \& Surgeons,

Morgan Stanley Children's Hospital of New York-Presbyterian,

3959 Broadway,

New York, NY 10032-1559, USA

e-mail: web2@columbia.edu 